\title{
The Effects of Social Capital and Individual Factors on Knowledge Sharing Among ERP System Users
}

\author{
Mohammad Bany Baker", Zawiyah M.Yusof* \\ ${ }^{\#}$ Research Center for Software Technology and Management, Faculty of Information Science and Technology, Universiti Kebangsaan \\ Malaysia, Bangi, Selangor, 43600, Malaysia \\ E-mail:mohammad_banibakr@yahoo.com,zawiy@ukm.edu.my
}

\begin{abstract}
Enterprise Resource Planning (ERP) system is a management technology that advocates an integrated approach to conducting business. Before organizations apply technology to improve the overall performance, they must understand what their employees need to use it. ERP systems are knowledge intensive, which require a high level of knowledge absorption and knowledge sharing among organizational members in order to be used successfully. Since the knowledge sharing is a key factor to using the ERP system, therefore this study aims to identify the social capital and individual factors affecting knowledge sharing among ERP users in small and medium-sized enterprises (SMEs). A quantitative method was employed using a self-administered questionnaire technique to collect data from 413 ERP users in Jordanian SMEs and SPSS software to analyze the data. This study found that social networks, trust, shared vision, self-efficacy, absorptive capacity; extrinsic motivation and intrinsic factors have influenced significantly on knowledge sharing among ERP users. Such a finding could provide guidelines for the management to enhance knowledge sharing among ERP users for successful ERP system usage.
\end{abstract}

Keywords — knowledge sharing; ERP system usage; individual; social capital; small and medium-sized enterprise

\section{INTRODUCTION}

Enterprise Resource Planning (ERP) systems are a set of standardized software and organization-wide database in which all business transactions are entered, recorded, processed, monitored, and reported. As a kind of processbased information systems, ERP supports multiple business functions like accounting and finance, human resources, production, and logistics. Therefore, ERP is critical for an organization to meet customer demand as it balances the process of internal production and external information feed [1], [2]. The ultimate objective of organizations investing in ERP systems is to gain the opportunities and advantages that they are promised with, once the implementation and routinization of the system are realized in the organization. These advantages have many dimensions, which can be categorized into operational, managerial, strategic, technological and organizational dimensions [3]. Small and medium enterprises (SMEs) are encountering a rapidly changing global market and the need to be able to respond to the requirements. ERP systems prepare the instrument for SMEs to address the competitive demand for the rapidly changing marketplace. It helps them to succeed to improve customer relations and management; reduce time, improve quality, increase sales volumes, manpower reduction and market share [4]. Globalization at industry level has highlighted the absence of the small industry concept at the operational area. In the organizing and guiding, companies with little financial power, employees or customers should act as large companies. Although these companies work as a small part of supply chain, but they exist in global markets. Therefore, it is necessary to improve their competitiveness continuously and gain their rights within such markets. This is the main reason for the ERP usage in the small and medium enterprises [5].

ERP system usage refers to how users employ the features of the system to perform a task [6]. System usage has been found to be a critical predictor of information system implementation success and thus for complex systems such as ERP systems, usage behavior needs to be effective and sophisticated for companies to realize inherent benefits. Typically, the higher the system usage by the end-user, the better the chances of firms' achieving ERP implementation goals and objectives [7].

The use of the ERP system is required for the day-to-day operations in a majority of organizations. The smooth operation of the system by the users could be beneficial to the organization. The adverse operation could mean the opposite which is why many organizations who have adopted ERP systems were disappointed as they expected it to achieve more business goals [8]. Through knowledge 
sharing, users can exchange what they know to create new knowledge jointly, enable correct operations and, consequently, facilitate system usage. ERP users gain $25 \%$ of their knowledge from training, 75\% from knowledge sharing process [9]. Employees' knowledge sharing may be invaluable in motivating the use of ERP systems among employees as employees are more inclined to ask peers for help when faced with an obstacle in using ERP system.

However, only little is known concerning the occurrence of knowledge sharing among team members when it comes to ERP systems [10]. For the ERP success, the formal barriers between the users of functions should share and integrate knowledge between functions and business units for a coordinated work [11]. Further successful usage of ERP in an organization requires getting rid of hindrances knowledge sharing. Chiu, et al. [12] indicate that "better knowledge sharing occurs through established trust relationships". Thus, knowledge sharing among ERP end users may be facilitated by their social capital.

Therefore, social capital provides individuals with the ability to access knowledge and information from their membership in social networks [13]. The friendships that an individual has with others impact their communications and exchanges [14], while the lack of trust between two individuals could prevent them from effectively transferring knowledge to each other. According to scholars, social capital also brings about knowledge sharing and develops intellectual capital, where social networks assist in the provision of knowledge sharing platforms [12]. Concerning the individual dimensions, the majority of authors are of the consensus that knowledge sharing largely depends on the characteristics of the individual like his experience, values, motivation, and beliefs. Similarly, Wang and Hou [15] demonstrated that individual motivators urge employee's to be willing to take part in knowledge sharing.

\section{MATERIALS AND METHODS}

\section{A. Knowledge Sharing}

Knowledge sharing as "the fundamental means, through which employees can contribute to knowledge application, innovation, and ultimately, the competitive advantage of the organization" [16] Knowledge sharing is "the provision of task information and know-how to help others and to collaborate with others to solve problems, develop new ideas, or implement policies or procedures." According to Van den Hooff [16], knowledge sharing can occur by direct interaction between individual (face-to-face), communication via online means, documents, handbooks, and expert lecturing. Knowledge sharing occurs through direct individual interaction, communication through online, documents, handbooks and expert lecturing.

ERP systems assist in bringing about work in the organization by streamlining business processes and combining business functions. Owing to the fact that ERP systems have their basis on best practices, the majority of organizations need to change their work processes in order to have a good fit with the architecture of ERP. Work activities and how they are performed and achieved have undergone a significant change. It is now incumbent upon users to collect knowledge regarding business rules and processes included in the ERP systems [13]. More importantly, the renowned complexity of ERP systems confines the amount of knowledge that users acquire prior to the actual use [17].

Knowledge sharing entails the connection of how to perform daily tasks and the how employees develop and exchange feedback, assumptions and working. Collaborating workers could generate enhanced ERP system success [10]. Aside from this, employees are able to update each other with work tips when they figure out how to achieve a useful task [17]. In other words, through knowledge sharing, users are enabled to exchange new knowledge collaboratively, correct operations and eventually, facilitate the use of the system - as such, knowledge sharing is a crucial factor in the successful use of the ERP system [18].

\section{B. Factors Affecting Knowledge Sharing}

This paper discussed on two factors that would affect to knowledge sharing among ERP system users namely social capital and individual.

1) Social Capital Factors: Social capital is described as the close interpersonal connection among individuals. It is a significant concept for organizational behavior as it encapsulates and promotes relationships that work towards successful collective action among members. Social capital is the total actual and potential resources included within and available via and from the relationships network possessed by the individual or social unit [19]. Social capital has three dimensions namely structural, cognitive and relational, with the last dimension being an affective part of the social capital, referring to the network relationship in terms of an interpersonal trust, the presence of shared norms and the connection with other individuals making up the network [20]. Social capital factors are described as the actors' ability to obtain benefits owing to their membership in social networks or structures [21]. It involves the individual's social networks and shared a vision with other members as well as a sense of trust in others forming the network [22]. Effective sharing of knowledge arises via the establishment of trust relationships [12]. Therefore, knowledge sharing among ERP users may be realized through the members' social capital.

Two hypotheses were constructed to identify whether or not a correlation exists between social capital and knowledge sharing. The first hypothesis is, H1: Knowledge sharing has a positive effect on ERP usage, and the second hypothesis is, H2: Social capital has a positive effect on ERP knowledge sharing. The $\mathrm{H} 2$ has three sub-hypotheses as follows:

- H2a: social network has a positive effect on ERP knowledge sharing.

- H2b: Trust has a positive effect on ERP knowledge sharing.

- H2c: Shared vision has a positive effect on ERP knowledge sharing.

According to the social network theory, social relationships that exist between individuals in the form of nodes and ties, where nodes refer to the individual actors forming the network and ties refer to the relationships among actors. Different individuals' ties add to different 
networks, and networks are categorized into three namely relational, structural and cognitive [23], [24]. The social network concept in the context of ERP posit that the ERP members' ability to develop strong connections among them and the weak connection with other ERP stakeholders in the user base is invaluable for countering the issues that arise in knowledge sharing and integration among members [11]. Company users interact among themselves, take part in information and knowledge sharing and explore ERP systems in a collaborative manner to achieve tasks. Moreover, it can be argued that individual interactive learning occurs in social networks within the boundary of the organization [25].

Researchers have defined trust in different ways, with the definition based on organizational and individual contexts. According to personality psychologists, trust is an individual characteristic while economists and sociologists describe the way institutions are developed to mitigate uncertainty and maximize trust in certain transactions of business [26]. In relation to this, Chiu, et al. [12] explained that the existence of trust between the two parties allows them to engage in cooperative interaction. Moreover, inter-personal trust is invaluable for successful teams and organizations, and for the creation of an ambiance that is conducive to sharing of knowledge. Trust plays a key role in developing and sustaining participants' relationship regarding the ERP project and in promoting activities that work towards knowledge sharing. Therefore, trust is an invaluable driver of relational behaviors and must be coupled with ERP projects processes [27].

Shared vision comprises of the organizational members' shared vision, goals, and aspirations. A mechanism bonds members together and assists the integration and combination of resources in different parts of the organization. Members who have a similar vision are expected to become partners in sharing and exchanging resource. Shared values and aims work as the binding agent among the human networks members, and brings about cooperation among them that eventually benefits the organization [24]. The important facet of the cognitive dimension is shared vision, which is " a bonding mechanism that helps different parts of an organization to integrate or to combine resources" [13]. Thus, shared vision is likely to be related to knowledge sharing among ERP users.

2) Individual Factors: Individuals form the core of organizational knowledge sharing and are responsible for the creation of knowledge that drives the sharing of knowledge created [28]. Studies revealed that efficacious employees are more likely to display intentions towards knowledge sharing $[29,30]$. It is important for employees to comprehend the complete range of their knowledge prior to sharing it. Forsman [19] contended that the amount and quality of individual tacit knowledge are the most difficult to gauge. The reported empirical findings regarding the relationship between rewards or incentives and knowledge sharing are mixed. Although the common belief is such that incentives (i.e. recognition and rewards) contribute to the achievement of knowledge sharing, particularly after the influence of extrinsic rewards has come under scrutiny in recent studies [29]. Moreover, there may be some risk in utilizing financial rewards to boost knowledge sharing as workers may perceive it as a controlling mechanism and as such, it may lessen creativity [20]. Along the same line of contention, self-efficacy and absorptive capacity are two individual factors that affect knowledge sharing. Under rewards and incentives, monetary as well as non-monetary rewards (e.g. training and development, feedback and different immaterial incentives) are covered. These compensation components have their basis on performance.

A hypothesis was constructed to identify the correlation between individual factor and ERP knowledge sharing. The hypothesis is, H3: Individual has a positive effect on ERP knowledge sharing. It has four sub-hypotheses as follows:

- H3a: Absorptive capacity has a positive effect on ERP knowledge sharing.

- H3b: Self-efficacy has a positive effect on ERP knowledge sharing.

- H3c: Extrinsic Motivation has a positive effect on ERP knowledge sharing.

- H3d: Intrinsic Motivation has a positive effect on ERP knowledge sharing.

According to Roberts, et al. [31], absorptive capacity is described as the individual's ability to identify, obtain, modify and employ external knowledge. Absorptive capacity to learn from colleagues at work positively influences a worker's attitudes towards sharing knowledge. Stated differently, individuals that possess high absorptive capacity are more likely to perceive the advantages of knowledge sharing that stems from their positive attitudes towards it [32, 33]. The more the individual is able to value, assimilate and employ the knowledge relayed, the more he is likely to be capable of understanding the way ERP best practices can be employed within firms [31]. In this context, Chang and Chou [34] state that individuals who lack absorptive capacity prevent knowledge sharing. In other words, individual ERP user's absorptive capacity plays a key role in the process of knowledge sharing [18].

Self-efficacy is described as the individual's perceived ability to conduct a specific task and to handle difficult situations while doing so. It influences behavior and decisions and is applied in the IT field where it is considered that computer self-efficacy is the belief of the individual that he/she is able to use computers in an effective manner in any situation. Self-efficacy considerably affects the ability of the individual to learn how to utilize computers. It is a significant predictor of the inclination towards ongoing learning [35]. It assists employees in knowledge sharing [36] and according to researchers employees that are highly efficacious contribute important knowledge and they are more likely to achieve particular tasks [17]. Meanwhile, knowledge self-efficacy generally arises in individuals who are convinced that their knowledge can assist in job-related problem solving and it can enhance their work efficacy [36]. Employees who perceive that they can contribute to enhancing organizational performance through knowledge sharing are expected to be more inclined to contribute and to be recipients of knowledge [29]. In relation to this, an individual has perceived self-efficacy influence his/her behaviors and decisions. Moreover, knowledge sharing refers to social interaction and cooperation and individuals who are highly self-efficacious are more likely to cooperate 
and contribute knowledge, and thus, promote the sharing of it [17].

Extrinsic motivation is the motivation arising from external sources such as expected evaluation or rewards, competition with peers, monitoring, or dictates from superiors [37]. Extrinsic motivation sheds light on what has to be considered when individuals take part in activities and adopt behaviors' leading to external rewards [38]. Knowledge sharing among employees requires time as well as effort but this could also lead to loss of the distinct value of the individual within an organization. As such, knowledge sharing takes place only when and individual perceives that the rewards exceed the cost [10]. General extrinsic motivations encapsulate financial rewards, formal acknowledgment and promotion on the job and thus, companies should provide rewards to workers who take part in sharing knowledge [39]. This holds true when employees are busy with day-to-day operations following the implementation of ERP system. It is also important for companies to boost knowledge sharing among users through the provision of rewards. It can, therefore, be stated that employees who are recipients of extrinsic benefits are expected to be more inclined towards knowledge sharing following the implementation of ERP [10].

Intrinsic motivation is the motivation to work because the activity is interesting and personally satisfying. It refers to doing a particular job because it is inherently enjoyable [37]. Intrinsic rewards generally refer to intangible rewards like respect, reputation, and praise. They make individuals feel satisfied and accomplished at work. In this regard, employees who provide invaluable knowledge to co-workers would feel accomplished and those who share knowledge with colleagues who are in need of it are intrinsically satisfied [13]. According to several studies, employees consider intrinsic rewards as significant [40] while Ko, et al. [41] claimed that while implementing an ERP system, a large amount of knowledge is complex and is characterized as tacit. This implicit knowledge is not easily observable by management and as such, management should depend on employees who share and transfer knowledge voluntarily with their co-workers [10].

\section{Method}

A self-administered questionnaire method was applied in order to collect the data required to achieve the research's objectives and answer the research questions, as well as to test the research hypotheses. A delivery and collection approach of hard copies of the questionnaire was chosen as the most appropriate method for this study to guarantee a high response rate. The questionnaire was distributed in various small and medium enterprises size located in Jordan. The questionnaire was to be completed by the ERP users and IT managers, financial and accounting managers and auditing managers working on ERP systems. 600 questionnaires were distributed to 32 small and medium organizations using ERP systems. A total of 413 completed responses were obtained.

\section{RESULTS AND DISCUSSION}

The results demographics of survey participants, as well as the backgrounds of their affiliated organizations, are shown in Table 1.

TABLE I

PROFILE OF RESPONDENTS (N=413)

\begin{tabular}{|c|c|c|}
\hline Category & $\mathbf{N}$ & $\%$ \\
\hline \multicolumn{3}{|l|}{ Demography } \\
\hline Male & 215 & 52 \\
\hline Female & 198 & 48 \\
\hline \multicolumn{3}{|c|}{ Highest education level } \\
\hline Diploma & 63 & 15.3 \\
\hline Bachelor degree & 294 & 71.2 \\
\hline Master degree & 48 & 11.6 \\
\hline $\mathrm{PhD}$ & 8 & 1.9 \\
\hline \multicolumn{3}{|c|}{ Usage of ERP system experience } \\
\hline$<5$ & 157 & 38 \\
\hline $5-10$ & 84 & 20.3 \\
\hline$>10$ & 172 & 41.6 \\
\hline \multicolumn{3}{|c|}{ Levels of ERP system usage } \\
\hline Operation & 279 & 67.6 \\
\hline Technical support & 61 & 14.8 \\
\hline Decision-making & 45 & 10.9 \\
\hline Management & 28 & 6.8 \\
\hline \multicolumn{3}{|l|}{ Type of company } \\
\hline Manufacturing & 20 & 4.8 \\
\hline Transportation & 28 & 6.8 \\
\hline Education & 34 & 8.2 \\
\hline Tourism & 36 & 8.7 \\
\hline IT company & 40 & 9.7 \\
\hline Retail & 41 & 9.9 \\
\hline Construction & 46 & 11.1 \\
\hline Pharmaceutical & 50 & 12.1 \\
\hline Financial service & 58 & 14.0 \\
\hline Health & 60 & 14.5 \\
\hline
\end{tabular}

\section{A. Construct Measurement}

The survey instrument was developed based on a comprehensive review of the existing literature. The questionnaire was then translated into Arabic, and a few revisions were made to adapt to ERP usage context. All the items were measured on a five-point Likert scale, anchored from 1 (strongly disagree) to 5 (strongly agree).

The number of items to measure trust and social networks was three, and two items were used to measure shared vision adopted from Kim and Lee [42]. Three items measuring absorptive capacity were adapted from Kwok and Gao [43] that evaluate the ability to identify, assimilate, transform, and apply external knowledge research. Three items were used to measure Self-efficacy from Shao, et al. [17]. The items measuring Extrinsic motivation were adapted from Chou, et al. [10] six items measuring Intrinsic motivation were adapted from Chou, et al. [10]. Six items measuring knowledge sharing were adapted from van den Hooff and de Ridder [44]. Those items measured individuals' attitudes towards and behaviors of knowledge sharing on ERP systems. Eleven items measuring ERP system usage were adapted from Chou, et al. [13] which focused on individual's ERP system usage with respect to decision support, work integration, and customer service. 


\section{B. Analysis and Results}

The psychometric properties of the instrument were evaluated using SPSS software in terms of internal consistency of scales. The analytical results show that all constructs used in this study have Cronbach's Alpha values as presented in Table 2, where the table illustrates the mean score and variance for each variable.

TABLE II

Descriptive ANALYsis For FACTORS AFFECTING KNOWLEDGE SHARING

\begin{tabular}{|l|c|c|c|c|}
\hline \multicolumn{1}{|c|}{ Factor } & Items & Mean & Variance & Alpha \\
\hline Social Capital Factor & & & & .751 \\
\hline Social network & SN1 & 1.56 & .548 & .727 \\
\hline & SN2 & 1.59 & .514 & \\
\hline & SN3 & 1.89 & .415 & \\
\hline Trust & T1 & 1.38 & .458 & .814 \\
\hline & T2 & 1.28 & .279 & \\
\hline & T3 & 1.59 & .514 & \\
\hline Shared vision & SV1 & 2.02 & .701 & .798 \\
\hline & SV2 & 1.97 & .766 & \\
\hline Individual Factor & & & & .947 \\
\hline Absorptive Capacity & AC1 & 1.57 & .435 & .905 \\
\hline & AC2 & 1.61 & .453 & \\
\hline & AC3 & 1.62 & .455 & \\
\hline Self -efficacy & SE1 & 1.58 & .410 & .881 \\
\hline & SE2 & 1.61 & .429 & \\
\hline & SE3 & 1.62 & .429 & \\
\hline Extrinsic motivation & EM1 & 1.67 & .563 & .843 \\
\hline & EM2 & 1.66 & .487 & \\
\hline & EM3 & 1.83 & .356 & \\
\hline & EM4 & 1.54 & .545 & \\
\hline & EM5 & 1.40 & .376 & \\
\hline & EM6 & 1.29 & .251 & \\
\hline Intrinsic motivation & IM1 & 1.62 & .533 & .832 \\
\hline & IM2 & 1.63 & .499 & \\
\hline & IM3 & 1.94 & .370 & \\
\hline & IM4 & 1.44 & .475 & \\
\hline & IM5 & 1.33 & .304 & \\
\hline & IM6 & 1.26 & .224 & \\
\hline & & & & \\
\hline
\end{tabular}

Multiple regression analysis was conducted to provide different outcomes to test the hypothesis postulated as depicted in Table 3 until Table 8.

TABLE III

ANALYSIS OF VARIANCE OF SOCIAL CAPITAL FACTORS AND KNOWLEDGE SHARING CONTRIBUTIONS OF INDIVIDUAL FACTORS

\begin{tabular}{|l|c|c|c|c|}
\hline \multicolumn{1}{|c|}{ Model } & $\begin{array}{c}\text { Sum of } \\
\text { Squares }\end{array}$ & df & $\begin{array}{c}\text { Mean } \\
\text { Square }\end{array}$ & F \\
\hline Regression & 52.694 & 3 & 17.565 & 384.451 \\
\hline Residual & 18.686 & 409 & .046 & \\
\hline Total & 71.380 & 412 & & \\
\hline
\end{tabular}

Table 4 showed the model summary of the three factors of social factor (Trust, Social Network, and Shared Vision) and knowledge sharing, the three independent variables were observed to have a positive correlation to the knowledge sharing as indicated by the positive $\mathrm{R}$ value of .859 . A computed $\mathrm{R}^{2}$ value of .738 suggests that the variables explain more than $73.6 \%$ of the variance in the knowledge sharing (with a standard error estimate of .213).
TABLE IV

RELATIVE CONTRIBUTION OF SOCIAL CAPITAL FACTORS

\begin{tabular}{|l|c|c|c|c|c|}
\hline \multirow{2}{*}{ Model } & \multicolumn{2}{|c|}{$\begin{array}{c}\text { Unstandardize } \\
\text { d Coefficients }\end{array}$} & $\begin{array}{c}\text { Standardized } \\
\text { Coefficients }\end{array}$ & \multirow{2}{*}{ t } & \multirow{2}{*}{ Sig. } \\
\cline { 2 - 5 } & $\mathbf{B}$ & $\begin{array}{c}\text { Std. } \\
\text { Error }\end{array}$ & Beta & & \\
\hline (Constant) & .341 & .036 & & 9.559 & .000 \\
\hline Social Network & .197 & .038 & .267 & 5.132 & .000 \\
\hline Trust & .441 & .034 & .584 & 12.992 & .000 \\
\hline Shared Vision & .055 & .017 & .103 & 3.196 & .002 \\
\hline
\end{tabular}

The result in Table 3 and Table 4 show that all social capital factors significantly contributing. Social network contributed the highest $(\beta=.267, \mathrm{t}=5.132, \mathrm{p}<.05)$, followed by trust $(\beta=.584, \mathrm{t}=12.992, \mathrm{p}<.05)$ and shared vision $(\beta=.103, \mathrm{t}=3.196 \mathrm{p}<.05)$. Thus, all social capital factors are positively affected to knowledge sharing.

TABLE V

ANALYSIS OF VARIANCE OF INDIVIDUAL FACTORS AND KNOWLEDGE SHARING

\begin{tabular}{|l|c|c|c|c|}
\hline \multicolumn{1}{|c|}{ Model } & $\begin{array}{c}\text { Sum of } \\
\text { Squares }\end{array}$ & df & $\begin{array}{c}\text { Mean } \\
\text { Square }\end{array}$ & F \\
\hline Regression & 57.303 & 4 & 14.326 & 415.223 \\
\hline Residual & 14.077 & 408 & .035 & \\
\hline Total & 71.380 & 412 & & \\
\hline
\end{tabular}

The model is a summary of the four factors of individual factor (self-efficacy, absorptive capacity, extrinsic motivation and intrinsic motivation) and knowledge sharing, the four independent variables were observed to have a positive correlation to the knowledge sharing as indicated by the positive $\mathrm{R}$ value of .896 . A computed $\mathrm{R}^{2}$ value of .803 suggests that the variables explain more than $80.1 \%$ of the variance in the knowledge sharing (with a standard error estimate of 0.183 ).

TABLE VI

ANALYSIS RELATIVE CONTRIBUTIONS OF INDIVIDUAL FACTORS

\begin{tabular}{|l|c|c|c|c|c|}
\hline \multicolumn{1}{|c|}{ Model } & \multicolumn{2}{|c|}{$\begin{array}{c}\text { Unstandardized } \\
\text { Coefficients }\end{array}$} & $\begin{array}{c}\text { Standardized } \\
\text { Coefficients }\end{array}$ & t & Sig. \\
\hline & B & $\begin{array}{c}\text { Std. } \\
\text { Error }\end{array}$ & Beta & & \\
\hline (Constant) & .244 & .034 & & 7.214 & .000 \\
\hline $\begin{array}{l}\text { Absorptive } \\
\text { Capacity }\end{array}$ & .281 & .039 & .394 & 7.262 & .000 \\
\hline $\begin{array}{l}\text { Self- } \\
\text { efficacy }\end{array}$ & .081 & .033 & .119 & 2.481 & .014 \\
\hline $\begin{array}{l}\text { Extrinsic } \\
\text { Motivation }\end{array}$ & .071 & .034 & .084 & 2.084 & .038 \\
\hline $\begin{array}{l}\text { Intrinsic } \\
\text { Motivation }\end{array}$ & .307 & .051 & .344 & 5.987 & .000 \\
\hline
\end{tabular}

The result in Table 5 and Table 6 show that all individual factors contribute significantly. Intrinsic motivation contributed the highest $(\beta=.344, \mathrm{t}=5.987, \mathrm{p}<.05)$, followed by absorptive capacity $(\beta=.199, \mathrm{t}=2.481, \mathrm{p}<.05)$, extrinsic motivation $(\beta=.084, t=2.084, p<.05)$ and selfefficacy $(\beta=.394, t=7.262, p<.05)$. Thus, all individual factors are positively affected to knowledge sharing. 
TABLE VII

ANALYSIS OF VARIANCE OF KNOWLEDGE SHARING AND ERP SYSTEM USAGE

\begin{tabular}{|l|c|c|c|c|}
\hline \multicolumn{1}{|c|}{ Model } & $\begin{array}{c}\text { Sum of } \\
\text { Squares }\end{array}$ & df & $\begin{array}{c}\text { Mean } \\
\text { Square }\end{array}$ & F \\
\hline Regression & 25.853 & 1 & 25.853 & 142.906 \\
\hline Residual & 74.353 & 411 & .181 & \\
\hline Total & 100.205 & 412 & & \\
\hline
\end{tabular}

The model summary of knowledge sharing and ERP system usage, knowledge sharing was observed to have a positive correlation to ERP system usage as indicated by the positive $\mathrm{R}$ value of .508 . A computed $\mathrm{R}^{2}$ value of .258 suggests that the variables explain more than $25.6 \%$ of the variance in the ERP system usage (with a standard error estimate of .425).

TABLE VIII

Relative CONTRIBUtion Of KNOWLEDGe SHARING

\begin{tabular}{|l|c|c|c|c|}
\hline \multicolumn{1}{|c|}{ Model } & \multicolumn{2}{|c|}{$\begin{array}{c}\text { Unstandardized } \\
\text { Coefficients }\end{array}$} & $\begin{array}{c}\text { Standardized } \\
\text { Coefficients }\end{array}$ & t \\
\hline & B & Std. Error & Beta & \\
\hline (Constant) & .639 & .074 & & 8.658 \\
\hline $\begin{array}{l}\text { Knowledge } \\
\text { Sharing }\end{array}$ & .602 & .050 & .508 & 11.954 \\
\hline
\end{tabular}

The result in the Table 7 and Table 8 show that the relative contribution of knowledge sharing to the variance in the dependent measure (ERP system usage). In term of predicting ERP system usage attribution, knowledge sharing $(\beta=.508, \mathrm{t}=11.954, \mathrm{p}<.05)$ is contributed significantly. Thus, knowledge sharing positively affect ERP system usage.

Based on the results this study proposed the knowledge sharing model as shown in Fig. 1.

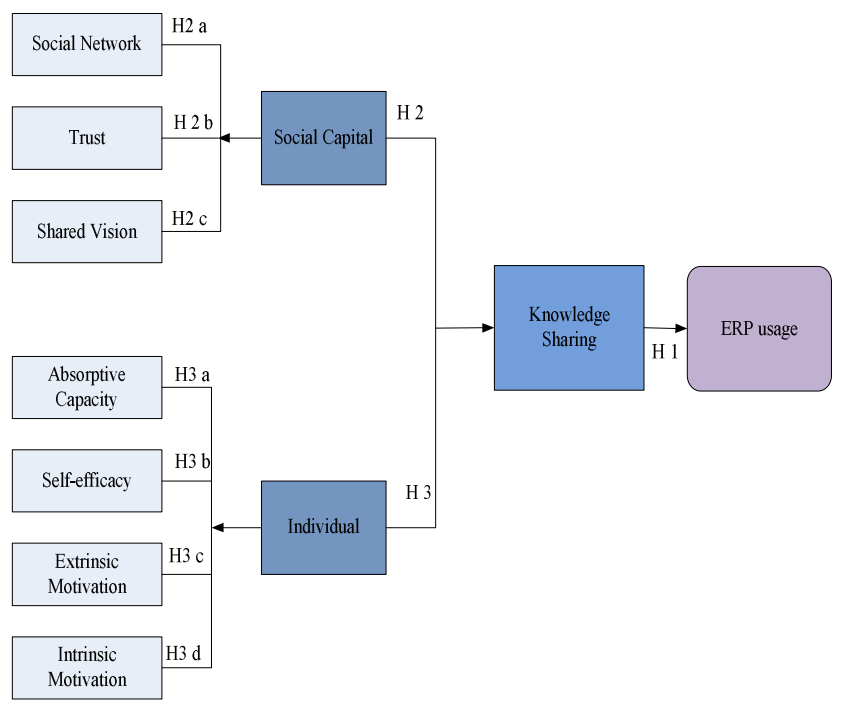

Fig. 1 The proposed model

Knowledge sharing has a key role to play in the three ERP usage dimensions namely decision support, work integration and customer service. Users who are willing to continually learn are more likely to promote the use of ERP as evidenced by prior studies like Chou, et al. [13]. This may be related to the fact that ERP systems lead to business process engineering and changes in the work processes. Knowledge obtained from the pre-implementation training is limited but it enables the users to be familiar with the effective use of the software. In this case, after an employee picks up on how to perform a specific task, his peers can quickly learn from him and hone their skills with such learning [17]. In other words, knowledge sharing may promote ERP use, and knowledge sharing impacts the three ERP dimensions of decision support, work integration and customer service. Social capital was revealed to significantly impact on the three ERP knowledge sharing conditions.

The underpinning rationale behind the result includes; first, the social network relationships can play the role of an efficient information-screening and distribution process for the members of the network that may facilitate ERP learner's learning and knowledge exchange. Second, people who lack trust often fail to learn [14], [36]. This supports the notion that in the context of individuals, trust encourages the accessibility to the social network, inclination for knowledge-exchange and the ERP knowledge use. Third, a shared vision can act as a basis for the observation and interpretation of the environment that could assist individuals to observe the potential value of learning resources and coordinating the understanding of users in various functions and levels [13].

The results from analysis revealed that social capital by virtue of its ties to the social network, trust, and shared vision plays a role as resources for ERP knowledge sharing and transfer that in turn, forms the conditions for the sharing of ERP knowledge. The results also showed the significant influence of self-efficacy on knowledge sharing that is aligned with prior studies [17]. In other words, individuals who are highly self-efficacious are more inclined towards sharing their knowledge with their peers after ERP implementation. Chou, et al. [10], [32] also found that intrinsic motivation and extrinsic motivation affect knowledge sharing among ERP users. In addition, the finding also showed that absorptive capacity affects knowledge sharing in such a way that the former significantly facilitates knowledge sharing.

\section{CONCLUSIONS}

Knowledge sharing is considered as an important factor with regards to successful of ERP system. The significance of knowledge sharing among ERP members was evidenced in different topics as discussed in this study. The advantages of good knowledge sharing practice in successful ERP call for efforts to achieve sustainable knowledge sharing among organization's employees. Previous studies have signified the positive relationship between social capital and knowledge sharing. This study found that trust, social network, and shared vision have a direct impact on knowledge sharing among ERP users. The examination of the effects of absorptive capacity on knowledge sharing showed a positive impact. Knowledge sharing calls for interactions between the sources of knowledge and its recipients but it is almost impossible for the knowledge recipients of ERP systems to directly interact with the sources as the systems do not provide a description of the task and process-related knowledge. With regards to individual factors, extrinsic motivation was effective for ERP user's willingness to 
knowledge sharing with colleagues. The findings indicate that perceptions of extrinsic motivation encouragement of knowledge sharing influence ERP user's willingness to share knowledge. The results reveal that intrinsic motivation in an organization is a central condition for successful knowledge sharing, where intrinsic motivation directly effect on willingness to share knowledge among ERP users. Moreover, the results show a positive significant relationship between self-efficacy and knowledge sharing and that self-efficacy help ERP users in sharing knowledge.

\section{ACKNOWLEDGMENT}

This research was funded by Universiti Kebangsaan Malaysia under the GUP-2014-007 research grant scheme.

\section{REFERENCES}

[1] S. Zhang, P. Gao, and Z. Ge, "Factors impacting end-users' usage of ERP in China," Kybernetes, vol. 42, pp. 1029-1043, 2013.

[2] M. Al-Mashari and H. Al-Mosheleh, "Enterprise Resource Planning of Business Process Systems," UK Academy for Information Systems Paper 2, 2015.

[3] L. Raymond, S. Rivard, and D. Jutras, "Evaluating readiness for ERP adoption in manufacturing SMEs," International Journal of Enterprise Information Systems (IJEIS), vol. 2, pp. 1-17, 2006.

[4] M. Haddara and O. Zach, "ERP systems in SMEs: A literature review," in System Sciences (HICSS), 44th Hawaii International Conference, 2011, pp. 1-10.

[5] C. Leyh, Critical Success Factors for ERP Projects in Small and Medium-Sized Enterprises-The Perspective of Selected ERP System Vendors, in Multidimensional Views on Enterprise Information Systems, Dresden, Germany: Springer. 2016

[6] J. Nwankpa and Y. Roumani, "Understanding the link between organizational learning capability and ERP system usage: An empirical examination," Computers in Human Behavior, vol. 33, pp. 224-234, 2014

[7] J. K. Nwankpa, "ERP system usage and benefit: A model of antecedents and outcomes," Computers in Human Behavior, vol. 45, pp. 335-344, 2015.

[8] P. Helo, P. Anussornnitisarn, and K. Phusavat, "Expectation and reality in ERP implementation: consultant and solution provider perspective," Industrial Management \& Data Systems, vol. 108, pp. 1045-1059, 2008.

[9] W. Wang, L. Liu, Y. Feng, Z. Shao, and L. Gao, "Comprehensive understanding the inhibitors and enablers of knowledge transfer in ERP assimilations: A multi-case study," in PACIS, 2014, pp.168

[10] H.-W. Chou, Y.-H. Lin, H.-S. Lu, H.-H. Chang, and S.-B. Chou, "Knowledge sharing and ERP system usage in post-implementation stage," Computers in Human Behavior, vol. 33, pp. 16-22, 2014.

[11] S. Ebrahimi, O. Ibrahim, A. Hussin, R. Che, and D. Sedera, "Efficiency of knowledge integration in enterprise systems implementation," in PACIS, 2013, p. 254

[12] C.-M. Chiu, M.-H. Hsu, and E. T. Wang, "Understanding knowledge sharing in virtual communities: an integration of social capital and social cognitive theories," Decision Support Systems, vol. 42, pp. 1872-1888, 2006

[13] H.-W. Chou, H.-H. Chang, Y.-H. Lin, and S.-B. Chou, "Drivers and effects of post-implementation learning on ERP usage," Computers in Human Behavior, vol. 35, pp. 267-277, 2014.

[14] C.-Y. Yao, C.-C. Tsai, and Y.-C. Fang, "Understanding social capital, team learning, members'e-loyalty and knowledge sharing in virtual communities," Total Quality Management \& Business Excellence, vol. 26, pp. 619-631, 2015.

[15] W.-T. Wang and Y.-P. Hou, "Motivations of employees' knowledge sharing behaviors: A self-determination perspective," Information and Organization, vol. 25, pp. 1-26, 2015.

[16] B. Van den Hooff, "Committed to share: commitment and CMC use as antecedents of knowledge sharing," Knowledge and process management, vol. 11, pp. 13-24, 2004.

[17] Z. Shao, T. Wang, and Y. Feng, "Impact of organizational culture and computer self-efficacy on knowledge sharing," Industrial Management \& Data Systems, vol. 115, pp. 590-611, 2015.
[18] J.-H. Park, H.-J. Suh, and H.-D. Yang, "Perceived absorptive capacity of individual users in performance of enterprise resource planning (ERP) usage: the case for Korean firms," Information \& Management, vol. 44, pp. 300-312, 2007.

[19] R. Forsman, "How to promote knowledge sharing in organizations using the psychological contract as a management tool.," Master thesis, University of Oulu, Oulu, Finland, 2014.

[20] A. Cabrera, W. C. Collins, and J. F. Salgado, "Determinants of individual engagement in knowledge sharing," The International Journal of Human Resource Management, vol. 17, pp. 245-264, 2006.

[21] A. Portes and E. Vickstrom, Diversity, social capital, and cohesion, Migration: Economic Change, Social Challenge, C. Dustmann, Ed. Oxford, United Kingdom: Oxford University Press, 2015.

[22] J. Lee, J.-G. Park, and S. Lee, "Raising team social capital with knowledge and communication in information systems development projects," International Journal of Project Management, vol. 33, pp. 797-807, 2015.

[23] C. Lechner, K. Frankenberger, and S. W. Floyd, "Task contingencies in the curvilinear relationships between intergroup networks and initiative performance," Academy of Management Journal, vol. 53, pp. 865-889, 2010.

[24] D. Paulin and K. Suneson, "Knowledge transfer, knowledge sharing and knowledge barriers-three blurry terms in KM," Leading Issues in Knowledge Management, Volume Two, vol. 2, p. 73, 2015.

[25] L. Gao, L. Liu, Y. Feng, and Q. Hu, "Understanding Individual Level ERP Assimilation from a Social Network Perspective: a Multi-Case Study.," in ECIS, 2014.

[26] D. Schniederjans and S. Yadav, "Successful ERP implementation: an integrative model," Business Process Management Journal, vol. 19, pp. 364-398, 2013.

[27] J.-G. Park and J. Lee, "Knowledge sharing in information systems development projects: Explicating the role of dependence and trust," International Journal of Project Management, vol. 32, pp. 153-165, 2014.

[28] N. Noor and S. Juhana "The influence of individual, organizational and technological factors on knowledge sharing in the private sector in Malaysia," in International Conference of Information Retrieval \& Knowledge Management (CAMP), 2012, pp. 167-171.

[29] I. Svetlik, E. Stavrou-Costea, and H.-F. Lin, "Knowledge sharing and firm innovation capability: an empirical study," International Journal of Manpower, vol. 28, pp. 315-332, 2007.

[30] D. De Clercq, D. Dimov, and N. Thongpapanl, "Structural and relational interdependence and entrepreneurial orientation in small and medium-sized enterprises: The mediating role of internal knowledge-sharing," International Small Business Journal, vol. 33, pp. 514-536, 2015.

[31] N. Roberts, P. S. Galluch, M. Dinger, and V. Grover, "Absorptive Capacity and Information Systems Research: Review, Synthesis, and Directions for Future Research," MIS quarterly, vol. 36, pp. 625-648, 2012.

[32] M. Kang and M.-J. Lee, "Absorptive capacity, knowledge sharing, and innovative behaviour of R\&D employees," Technology Analysis \& Strategic Management, pp. 1-14, 2016.

[33] L. Wang, P.-L. P. Rau, V. Evers, B. K. Robinson, and P. Hinds, "When in Rome: The Role of Culture \& Context in Adherence to Robot Recommendations," in Proceeding of the 5th ACM/IEEE International Conference on Human-robot Interaction, New York, 2010, p. 359-366.

[34] H.-H. Chang and H.-W. Chou, "Drivers and effects of enterprise resource planning post-implementation learning," Behaviour \& Information Technology, vol. 30, pp. 251-259, 2011.

[35] H.-F. Lin, "Knowledge sharing and firm innovation capability: an empirical study," International Journal of Manpower, vol. 28, pp. 315-332, 2007.

[36] L. Zaglago, C. Chapman, and H. Shah, "ERP System Implementation and Tacit Knowledge Sharing," in Proceedings of the World Congress on Engineering, 2016, pp. 251-256

[37] Z. al-Salti, "An investigation of knowledge transfer in information systems (IS) outsourcing," PhD thesis, Brunel University, London 2011.

[38] H. Rode, "To share or not to share: the effects of extrinsic and intrinsic motivations on knowledge-sharing in enterprise social media platforms," Journal of Information Technology, vol. 31, pp. 152-165, 2016.

[39] N. S. Safa and R. Von Solms, "An information security knowledge sharing model in organizations," Computers in Human Behavior, vol. 57, pp. 442-451, 2016. 
[40] G. Huber, "Transfer of Knowledge in Knowledge Management Systems: Unexplored Issues and Suggested Studies," in The Essentials of Knowledge Management, ed: Springer, pp. 199-212, 2015

[41] D.-G. Ko, L. J. Kirsch, and W. R. King, "Antecedents of knowledge transfer from consultants to clients in enterprise system implementations," MIS quarterly, pp. 59-85, 2005.

[42] S. Kim and H. Lee, "The impact of organizational context and information technology on employee knowledge - sharing capabilities," Public Administration Review, vol. 66, pp. 370-385, 2006.

[43] S. H. Kwok and S. Gao, "Attitude towards knowledge sharing behavior," Journal of Computer Information Systems, vol. 46, pp. 45$51,2005$.

[44] B. van den Hooff and J. A. de Ridder, "Knowledge sharing in context: the influence of organizational commitment, communication climate and CMC use on knowledge sharing," Journal of Knowledge Management, vol. 8, pp. 117-130, 2004. 